\title{
Using Quick Response Code in Food Packaging for Traceability and Marketing Strategies
}

\author{
Joao Guilherme de Camargo Ferraz Machado ${ }^{1 *}$, Jose Flavio Diniz Nantes ${ }^{2}$ and Fabiana Cunha Viana \\ Leonelli $^{3}$
}

${ }^{1}$ Sao Paulo State University (UNESP), Faculty of Sciences and Engineering, Tupa-SP, Brazil

${ }^{2}$ Federal University of Sao Carlos, Exact and Technology Sciences Center, Sao Carlos-SP, Brazil

${ }^{3}$ University of Sao Paulo (USP), Faculty of Animal Science and Food Engineering, Pirassununga-SP, Brazil

*Corresponding author: Joao Guilherme de Camargo Ferraz Machado, Sao Paulo State University(UNESP), Faculty of Sciences and Engineering, Brazil.

Received Date: February 27, 2019

Published Date: March 28, 2019

\begin{abstract}
The use of Quick Response Code (QR code) in agri-food products packaging has been providing a new channel of communication and relationship between company and consumer. In food retailing, in the absence of sellers packs communicate with consumers and, when used as a marketing strategy or tool facilitating traceability, can help consumers interpret the available information on the labels. The mobile tagging strategies allow available information and entertainment with innovative actions to different segments, expanding the labels communications capabilities beyond traditional information weight, validity, and nutritional data. Although the growth potential of this technology is significant, use the packaging still limited, and companies lose the opportunity to differentiate the offer, providing additional content and sometimes customized. However, to leverage its use is necessary for companies to show clearly the QR code on packaging and also indicate to consumers how to make use of this technology, taking advantage of the available information so that in future they may use them in the decision shopping process.
\end{abstract}

Keywords: Agri food products; Marketing strategies; Packaging; QR code; Traceability

\section{Introduction}

The Quick Response Code (QR code) has become more and more frequent in packaging and printed publicity materials used in advertising and promotion campaigns. In Brazil, many consumers still do not understand the use of this new figure printed on the packaging, so although QR code is gaining commercial popularity due to the growth of mobile technology, its use is reduced in Western countries, compared to Asian countries.

The packaging plays essential functions of protection, packaging, and storage, as well as enabling the logistics of product distribution to the final destination, preserving its attributes. In food retailing, where practically no sellers, packaging rests with the function to communicate to the consumer the product messages [1]. In this sense, [2] pointed out that the use of QR code as a marketing strategy assists in the promotion of the product or company, or even directing consumer choices.

\section{Discussion}

According to [3], the QR code has been widely used in packaging allowing the adoption of marketing actions (images of other products and coupons), the labeling of the product and the inclusion of commercial traceability information. In this case, concern about food safety and possible health risks added to the need for transparent information has increased the importance of traceability of such products [4]. The details of the traceability information add value to food products to meet legal issues of safety and quality assurance, increasing confidence and consumer satisfaction.

The traceability associated with the use of the QR code may provide information and transparency of the productive chains and, thus ensure the quality and safety of the products [5]. The main benefit of this technology is the ease of use because it is only 
necessary to scan the code with a Smartphone to access the data available in a digital way.

Marketing activities developed with the mobile phone's help, to leverage the construction of a satisfactory and lasting relationship between companies and customers are called mobile marketing strategies [6]. When directed on packaging and labels, mobile tagging - providing data on mobile devices, usually by reading a two-dimensional bar code through a camera phone - enables taking information and entertainment to different segments through innovative actions. With this technology, the label expands its communication capabilities beyond the traditional presentation of information on the weight, validity or nutritional data. Thus, the use of mobile tags may influence the formation of consumer's opinion [7], making packing a highly effective means of communication for businesses.

The industry has increasingly stamped the QR code on food packaging, allowing consumer instant access to gifts, services, and information hosted on the Internet. Criticism, in this case, is being pointed to frequently frustrating experiences that brands offer to customers, leading them to sites that were not prepared for the mobile platform, or where it isn't possible to find the product announcement, or else the packing information cannot be found.

Whereas consumers are increasingly interested in practical information on the product, we believe that they are predisposed to use their Smartphone to access information from the manufacturer/producer at the selling point, assisting in decisionmaking [1]. In retail, marketing communication using QR code can provide consumers with functional benefits such as business and convenience information rather than utilities, in the case of a more enjoyable shopping experience.

Consumers recognize the importance of the information on the label, and they are more interested in practical information, such as preparation methods, security assurance, quality brand and its product [8]. Found in consumers preference for traceability information, having observed a predisposition for more trade information and less technical one, possibly because the traceability information (technical) are less known and of little domain.

Even with a plentiful supply of differentiation opportunity, companies have been unable to identify the best way to maximize the advantages of using the QR code that offers interactivity to be scanned, allowing access to different content, increasing the potential for interactivity through clicks or performing a specific task to receive a special offer, for example. Using this tool, developed for quick and easy access to content on Smartphone, consumers can feel more connected to the brand [9].

\section{Conclusion}

In general, consumers have difficulties in interpreting food labels accurately or objectively, suggesting a gap in the information that guides the purchase decision. In this sense, a mobile tagging system can provide access to accurate and relevant information by reading the $\mathrm{QR}$ code on the product packaging, making it possible to retrieve information stored in a central database. Another advantage is that this information can be customized according to the preferences and needs of each group of consumers, becoming an excellent tool for the supply of differentiation strategy, market segmentation, and product positioning.

This trend suggests that soon, the mobile phone plays an essential role in the purchasing process, enabling the consumer to obtain more information and make better choices and acquisitions. However, it is necessary a better understanding of how consumers interact with the QR code, the use in purchasing decisions and what information value most. Understanding these issues will contribute to the consolidation of the use of this technology uses and, above all, the transparency and availability of information about the production process, reinforcing the importance of traceability and quality assurance in food.

\section{Acknowledgment}

The authors acknowledge the Scientific and Technological Development Council-CNPq (408819/2013-8) for financial support that enabled the execution of this research.

\section{Conflict of interest}

No conflict of interest.

\section{References}

1. Machado JGCF, Nantes JFD, Leonelli FCV (2019) Do I know what I eat? The use of QR code in Food Packaging to Provide Traceability Information. International Journal of Advanced Engineering Research and Science 6(1): 45-58.

2. Walsh A (2009) Quick Response Codes and Libraries. Library Hi Tech News 26(5/6): 7-9.

3. Machado JGCF, Nantes JFD, Leonelli FCV (2014) Entraves e perspectivas para aplicação do QR code em produtos agroalimentares. Proceedings of 34th Encontro Nacional de Engenharia de Produção, p. 12.

4. Song M, Liu L, Wang Z, Nanseki T (2008) Consumers' attitudes to food traceability system in China-evidences from the pork market in Beijing. Journal of the Faculty of Agriculture, Kyushu University 53(2): 569-574.

5. Pieniak Z, Monika K, Kowrygo B, Verbeke W (2011) Consumption patterns and labelling of fish and fishery products in Poland after the EU accession. Food Control 22(6): 843-850.

6. Kotler P, Keller K (2006) Administração de marketing 12th ed. Pearson Prentice Hall, Sao Paulo, Brazil.

7. Corrêa MI de S, Souza ACR de, Marçal MCC (2012) 0 uso do QR Code na gestão da comunicação: o caso da rede social Wine Tag. Informe: Estudos em Biblioteconomia e Gestão da Informação 1(1): 118-132.

8. Schröder U (2008) Challenges in the traceability of seafood. Journal of Consumer Protection and Food Safety 3: 45-48

9. Shin DH, Jung J, Chang BH (2012) The psychology behind QR codes: users experience perspective. Computers in Human Behavior 28(4): 1417-1426. 